\title{
Gender Differences of Occupational Stress Associated with Suicidal Ideation among South Korean Employees: The Kangbuk Samsung Health Study
}

\author{
Sun-Young Kim¹, Dong-Won Shin ${ }^{1}$, Kang-Seob Oh¹, Eun-Jin Kim², \\ Yang-Ri Park ${ }^{2}$, Young-Chul Shin ${ }^{1,2 *} \bowtie$, and Se-Won Lim ${ }^{1,2 *} \bowtie$ \\ ${ }^{1}$ Department of Psychiatry, Kangbuk Samsung Hospital, Sungkyunkwan University School of Medicine, Seoul, Republic of Korea \\ ${ }^{2}$ Workplace Mental Health Institute, Kangbuk Samsung Hospital, Sungkyunkwan University School of Medicine, Seoul, Republic of Korea
}

\begin{abstract}
Objective In this study, the relationship between occupational stress and suicidal ideation was investigated, focusing on gender differences among Korean employees.

Methods Cross-sectional data for 53,969 workers were collected at Kangbuk Samsung Hospital health screening centers. Risk of suicidal ideation was assessed using a self-reported questionnaire examining suicidal ideation during the past year. Occupational stress was measured using 24 items of the Korean Occupational Stress Scale-Short Form (KOSS-SF). Logistic regression analysis was employed to estimate the odds ratios and $95 \%$ confidence intervals of the relationships between suicidal ideation and components of occupational stress.

Results In multivariable-adjusted models, all job stress contributed to increased risk of suicidal ideation in males. Most subscales, except insufficient job control and organizational system, were risk factors of suicidal ideation in females. Further adjustments for depression markedly attenuated this relationship. However, the effects of insufficient job control and lack of reward on suicidal ideation remained significant in males, and interpersonal conflict remained significant in females.
\end{abstract}

Conclusion The results suggest that occupational stress plays a significant role in increasing risk of suicidal ideation through elevation of depressive symptoms. Gender differences in components of occupational stress associated with suicidal ideation were also observed.

Psychiatry Investig 2018;15(2):156-163

Key Words Suicide, Occupational stress, Gender.

\section{INTRODUCTION}

The number of deaths from suicide has increased during the last two decades in Korea. Suicide was ranked as the tenth leading cause of death in 1992 but increased to the fourth lead-

\footnotetext{
Received: January 25, 2017 Revised: April 9, 2017

Accepted: May 31, 2017 Available online: November 29, 2017

$\triangle$ Correspondence: Se-Won Lim, MD, PhD

Department of Psychiatry, Kangbuk Samsung Hospital, Sungkyunkwan University School of Medicine, 29 Saemunan-ro, Jongno-gu, Seoul 03181, Republic of Korea

Tel: +82-2-2001-2591, Fax: +82-2-2001-2211, E-mail: knappe@paran.com

$\triangle$ Correspondence: Young-Chul Shin, MD, PhD

Department of Psychiatry, Kangbuk Samsung Hospital, Sungkyunkwan University School of Medicine, 29 Saemunan-ro, Jongno-gu, Seoul 03181, Republic of Korea

Tel: +82-2-2001-2591, Fax: +82-2-2001-2211, E-mail: yshin523@hanmail.net

*These authors contributed equally to this work.

(c) This is an Open Access article distributed under the terms of the Creative Commons Attribution Non-Commercial License (http://creativecommons.org/licenses/bync/4.0) which permits unrestricted non-commercial use, distribution, and reproduction in any medium, provided the original work is properly cited.
}

ing cause in 2008, accounting for 27.3 deaths per 100,000 people in $2014 .^{1}$

Occupational stress can damage health and quality of life and can also lead to direct social and economic costs. ${ }^{2-5}$ Previous studies have proposed that increasing occupational stress could be associated with the increasing prevalence of depressive disorder. ${ }^{6-10}$ Given that depressive symptoms are strongly related to suicide, it is necessary to investigate the relationship between occupational stress and suicide; however, relatively few studies have examined this relationship. Adverse working conditions and work attitudes have been shown to play significant roles as suicidal risk factors in cohort studies of occupational groups. ${ }^{11,12}$ Long work hours, heavy workloads, and low levels of social support seem to be related to suicide in Japan. ${ }^{13}$ A recent controlled psychological autopsy study in Hungary has revealed an association between concern over work prospects and suicide. ${ }^{14}$ However, these studies did not include large samples or multiple covariates relat- 
ed to suicidal ideation.

Conceptually, the role of gender differences in stress dynamics has not been clearly specified. However, Beehr and Schuler have reported that gender may be viewed either as a moderator between stressor and stress responses or as a direct predictor of stressors, stress symptoms, and/or coping responses. ${ }^{15}$ According to 2014 study of suicide by gender, which was examined in Korean Statistical Infromation Service (KOSIS), there are the difference in suicide rates for males and females, accounting for 38.4 deaths for 100,000 in male and 16.1 deaths for 100,000 people in female. ${ }^{16}$ In all Organisation for Economic Co-operation and Development (OECD) countries, varying degrees in different countries, males had a much higher rate of suicides than female with differences ranging from 1.6 deaths for 100,000 (South Africa) to 42.6 deaths for 100,000 (Lithuania). ${ }^{17}$ Although the difference in work according to sex has been decreasing in most developed countries, it is still obvious that there are certain gender specific roles in workplace, which have a possible impact on occupational stress and suicidal idea. However, few studies have taken gender differences into account.

The purpose of this study was to explore the relationship between occupational stress and suicidal ideation, focusing on gender difference.

\section{METHODS}

\section{Participants}

From May 2012 through April 2013, data from 56,581 employees were collected at Kangbuk Samsung Hospital health screening centers in Seoul and Suwon, South Korea. The current study is a cross-sectional design of working-age employees (15-64 yrs of age) who were medically stable and did not require any acute interventions. Those who had neurologic illnesses including stroke, brain hemorrhage, transient ischemic attack were excluded.

All participants completed self-reported type questionnaires about suicidal ideation, occupational stress, and depressive symptoms.

The study protocol was approved by the Institutional Review Board of Kangbuk Samsung Hospital (IRB No. 2013-01-217). The requirement for informed consent was waived because we used only de-identified data routinely collected during health screening visits.

\section{Study variables and measurements}

\section{Assessment of depression and suicidal ideation}

We used the Center for Epidemiologic Studies Rating Scale for Depression (CES-D) to evaluate depressive symptoms and severity. ${ }^{18}$ Cho and Kim validated the reliability of the Korean version of the CES-D. Internal consistency alpha scores ranged from 0.84 to 0.91 in South Korea. ${ }^{19}$

The CES-D consists of 20 items related to characteristic symptoms of depression. The score for each item was rated on a scale of $0-4$ points.

Suicidal ideation was assessed with the self-reported question "For the past 1 year, have you ever thought about killing yourself?" The response was dichotomous as either "Yes" or "No."

\section{Assessment of occupational stress}

Occupational stress was measured using 24 items of the Korean Occupational Stress Scale, Short Form (KOSS-SF), a selfreport questionnaire designed for estimating unique and specific occupational stressors among Korean employees. Chang et al. have validated the reliability of the KOSS-SF in a nationwide epidemiological study (NSDSOS Project: 2002-2004) conducted in Korea.

The subscales of the KOSS-SF address job demands (four items, Cronbach's alpha: 0.58), insufficient job control (four items, Cronbach's alpha: 0.67), interpersonal conflict (three items, Cronbach's alpha: 0.55), job insecurity (two items, Cronbach's alpha: 0.73 ), organizational system (four items, Cronbach's alpha: 0.67), lack of rewards (three items, Cronbach's alpha: 0.72), and occupational climate (four items, Cronbach's alpha: 0.71). ${ }^{20}$ Supplementary Table 1 (in the online-only Data Supplement) presents details of each questionnaire item and the seven subscales. Each item in the questionnaire was scored using conventional 1-2-3-4 Likert scores for the response categories. Totals for KOSS-SF scores and seven subscale scores were calculated using a 100-point system. Based on the median of the converted scores, these scores were dichotomized into a high-stress group (top 50\%) and a lowstress group (bottom $50 \%$ ). ${ }^{21}$

\section{Demographic data and other variables}

Demographic information such as gender, age, marital status, duration of education (years) as well as clinical information including smoking history (pack years) and alcohol consumption was gathered by self-reported type questionnaire. For the measurement of alcohol consumption, we have used Korean version of Alcohol Use Disorders Identification Test (AUDIT). ${ }^{22}$

\section{Statistical analysis}

We compared demographic data, age, marital status, educational attainment, AUDIT, and smoking in the suicidal ideation group and control, and stratified the data by gender. Parametric variables were compared by t-test, and categorical data were analyzed using chi-square test. In a crude model, data 
for occupational stress were entered as independent variables. Logistic regression analyses were used to determine the relationship between suicidal ideation and occupational stress, which were performed step by step according to covariates. In model 1, demographic variables (age, marital, education, AUDIT, smoking) were additionally entered as covariates. In model 2, depression was adjusted to explore the effect of depression as a mediator between occupational stress and suicidal ideation. Considering gender differences in suicide, the data was stratified by gender in all of our regression models.

We set the level of statistical significance at 0.05 (two-sided). All statistical analyses were conducted using IBM SPSS Statistics for Windows, Version 18.0 (SPSS Inc., Chicago, IL, USA).

\section{RESULTS}

The general characteristics of the study participants are presented in Table 1. The 3,958 (7.00\%) participants with suicidal ideation comprised 2,612 men (5.56\%) and 1,346 women
(14.01\%). The mean age of the suicidal ideation group was $39.33 \pm 6.72$ years for men and $34.33 \pm 6.74$ years for women. The suicidal ideation group reported lower educational attainment and higher mean AUDIT score and smoking in both genders, as predicted. Depressive symptoms are closely related to suicidal ideation. The mean scores of depressive symptoms in males as measured by the CES-D were $14.31 \pm 10.03$ in the suicidal ideation group and $5.42 \pm 5.64$ in the control group. In females, the mean scores were $17.73 \pm 10.95$ in the suicidal ideation group and $7.43 \pm 7.42$ in the control group. In marital status, the rate of others (married, divorced, widowed, separated) in males [With suicidal ideation (SI) $=81.13 \%$, Without $\mathrm{SI}=85.40 \%$ ] was higher than that of females (With $\mathrm{SI}=$ 56.69\%, Without SI=64.39\%).

As presented in Table 2, all scores indicated that work stress was higher in the suicidal group than in the control group for both male and female workers. Multiple logistic regressions were performed to examine factors associated with suicidal ideation, and the adjusted odds ratios (ORs) are presented in

Table 1. General characteristics of participants by suicidal ideation and gender

\begin{tabular}{|c|c|c|c|c|c|c|}
\hline & \multicolumn{3}{|c|}{ Male $(\mathrm{N}=46,976)$} & \multicolumn{3}{|c|}{ Female $(\mathrm{N}=9,605)$} \\
\hline & $\begin{array}{c}\text { With SI } \\
(\mathrm{N}=2,612)\end{array}$ & $\begin{array}{l}\text { Without SI } \\
(\mathrm{N}=44,364)\end{array}$ & $\mathrm{p}$ & $\begin{array}{c}\text { With SI } \\
(\mathrm{N}=1,346)\end{array}$ & $\begin{array}{l}\text { Without SI } \\
(\mathrm{N}=8,259)\end{array}$ & $\mathrm{p}$ \\
\hline Age (years), mean $\pm S D$ & $39.33 \pm 6.72$ & $39.57 \pm 6.72$ & 0.088 & $34.33 \pm 6.74$ & $35.18 \pm 6.62$ & $<0.001$ \\
\hline Marital status, N (\%) & & & $<0.001$ & & & $<0.001$ \\
\hline Single & $493(18.87)$ & $6,478(14.60)$ & & $583(43.31)$ & $2,941(35.61)$ & \\
\hline Others* & $2,119(81.13)$ & $37,886(85.40)$ & & $763(56.69)$ & $5,318(64.39)$ & \\
\hline Education (years), mean $\pm \mathrm{SD}$ & $15.76 \pm 1.89$ & $16.10 \pm 1.72$ & $<0.001$ & $14.91 \pm 2.19$ & $15.41 \pm 2.10$ & $<0.001$ \\
\hline AUDIT, mean $\pm S D$ & $9.68 \pm 6.52$ & $8.12 \pm 5.30$ & $<0.001$ & $5.18 \pm 5.15$ & $3.74 \pm 4.04$ & $<0.001$ \\
\hline Smoking (pack years), mean \pm SD & $9.17 \pm 9.78$ & $7.68 \pm 8.71$ & $<0.001$ & $0.44 \pm 1.89$ & $0.21 \pm 1.21$ & $<0.001$ \\
\hline Total CESD, mean \pm SD & $14.31 \pm 10.03$ & $5.42 \pm 5.64$ & $<0.001$ & $17.73 \pm 10.95$ & $7.43 \pm 7.42$ & $<0.001$ \\
\hline
\end{tabular}

*married, divorced, widowed, separated. SI: suicidal ideation, AUDIT: Alcohol Use Disorder Identification Test, CESD: Center for Epidemiological Studies Depression

Table 2. Mean scores of KOSS-SF among participants with or without SI by gender

\begin{tabular}{|c|c|c|c|c|c|c|}
\hline & \multicolumn{3}{|c|}{ Male $(\mathrm{N}=46,976)$} & \multicolumn{3}{|c|}{ Female $(\mathrm{N}=9,605)$} \\
\hline & $\begin{array}{c}\text { With SI* } \\
(\mathrm{N}=2,612)\end{array}$ & $\begin{array}{l}\text { Without SI* } \\
(\mathrm{N}=44,364)\end{array}$ & $\mathrm{p}$ & $\begin{array}{c}\text { With SI* } \\
(\mathrm{N}=1,346)\end{array}$ & $\begin{array}{l}\text { Without SI* } \\
(\mathrm{N}=8,259)\end{array}$ & $\mathrm{p}$ \\
\hline Total KOSS-SF & $49.48 \pm 11.14$ & $43.08 \pm 10.07$ & $<0.001$ & $50.59 \pm 11.01$ & $45.18 \pm 10.30$ & $<0.001$ \\
\hline Job demand & $56.87 \pm 19.53$ & $51.91 \pm 18.32$ & $<0.001$ & $56.11 \pm 19.56$ & $52.54 \pm 19.45$ & $<0.001$ \\
\hline Insufficient job control & $39.10 \pm 15.60$ & $35.99 \pm 14.11$ & $<0.001$ & $45.82 \pm 16.86$ & $42.71 \pm 15.66$ & $<0.001$ \\
\hline Interpersonal conflict & $42.18 \pm 16.32$ & $36.81 \pm 14.19$ & $<0.001$ & $43.84 \pm 18.10$ & $38.08 \pm 15.27$ & $<0.001$ \\
\hline Job insecurity & $42.59 \pm 24.52$ & $33.41 \pm 22.05$ & $<0.001$ & $37.85 \pm 24.64$ & $31.10 \pm 22.24$ & $<0.001$ \\
\hline Organizational system & $48.07 \pm 15.46$ & $41.50 \pm 13.07$ & $<0.001$ & $49.21 \pm 15.48$ & $43.75 \pm 14.03$ & $<0.001$ \\
\hline Lack of reward & $75.20 \pm 20.61$ & $66.45 \pm 17.43$ & $<0.001$ & $76.72 \pm 20.65$ & $69.45 \pm 18.70$ & $<0.001$ \\
\hline Occupational climate & $42.34 \pm 17.07$ & $35.52 \pm 15.86$ & $<0.001$ & $44.58 \pm 18.13$ & $38.65 \pm 17.05$ & $<0.001$ \\
\hline
\end{tabular}

*student's t-test were used to compare the two groups of employees and data represented as mean \pm SD. Totals for KOSS-SF scores and seven subscale scores were calculated using a 100-point system. KOSS-SF: Korean Occupational Stress Scale-Short Form, SI: suicidal ideation 
Table 3. Associations between occupational stressors and suicidal ideation among male employees

\begin{tabular}{|c|c|c|c|c|c|c|c|c|c|}
\hline \multirow{2}{*}{$\mathrm{KOSS}_{-\mathrm{SF}^{\dagger}}$} & \multicolumn{3}{|c|}{ Crude model } & \multicolumn{3}{|c|}{ Model 1* } & \multicolumn{3}{|c|}{ Model 2* } \\
\hline & OR & $95 \% \mathrm{CI}$ & $\mathrm{p}$ & OR & $95 \% \mathrm{CI}$ & $\mathrm{p}$ & OR & $95 \% \mathrm{CI}$ & $\mathrm{p}$ \\
\hline Job demand & 1.35 & $1.24-1.47$ & $<0.001$ & 1.41 & $1.30-1.54$ & $<0.001$ & 1.00 & $0.91-1.10$ & 0.944 \\
\hline Insufficient job control & 1.33 & $1.10-1.62$ & 0.004 & 1.29 & $1.06-1.57$ & 0.010 & 1.27 & $1.03-1.57$ & 0.027 \\
\hline Interpersonal conflict & 1.52 & $1.37-1.68$ & $<0.001$ & 1.50 & $1.36-1.67$ & $<0.001$ & 1.05 & $0.94-1.17$ & 0.423 \\
\hline Job insecurity & 2.13 & $1.81-2.51$ & $<0.001$ & 2.05 & $1.74-2.42$ & $<0.001$ & 1.14 & $0.95-1.38$ & 0.158 \\
\hline Organizational system & 1.17 & $0.97-1.41$ & 0.098 & 1.21 & $1.01-1.46$ & 0.042 & 0.87 & $0.70-1.07$ & 0.192 \\
\hline Lack of reward & 1.81 & $1.66-1.98$ & $<0.001$ & 1.75 & $1.60-1.91$ & $<0.001$ & 1.28 & $1.16-1.40$ & $<0.001$ \\
\hline Occupational climate & 1.58 & $1.28-1.96$ & $<0.001$ & 1.62 & $1.31-2.02$ & $<0.001$ & 0.94 & $0.73-1.22$ & 0.661 \\
\hline
\end{tabular}

${ }^{*}$ demographics (age, marital, education, AUDIT, smoking) were entered as covariates in model 1 and CESD was adjusted in model $2,{ }^{\dagger}$ seven subscale scores of KOSS-SF were calculated using a 100-point system. Based on the median of the converted scores, a low-stress group (bottom 50\%) was reference group. KOSS-SF: Korean Occupational Stress Scale-Short Form, AUDIT: Alcohol Use Disorder Identification Test, CESD: Center for Epidemiological Studies Depression

Table 4. Associations between occupational stressors and suicidal ideation among female employees

\begin{tabular}{|c|c|c|c|c|c|c|c|c|c|}
\hline \multirow{2}{*}{ KOSS-SF ${ }^{\dagger}$} & \multicolumn{3}{|c|}{ Crude model } & \multicolumn{3}{|c|}{ Model $1^{*}$} & \multicolumn{3}{|c|}{ Model 2* } \\
\hline & OR & $95 \% \mathrm{CI}$ & $\mathrm{p}$ & OR & $95 \% \mathrm{CI}$ & $\mathrm{p}$ & OR & $95 \% \mathrm{CI}$ & $\mathrm{p}$ \\
\hline Job demand & 1.23 & $1.09-1.40$ & 0.001 & 1.28 & $1.13-1.46$ & $<0.001$ & 0.95 & $0.83-1.10$ & 0.500 \\
\hline Insufficient job control & 1.17 & $0.90-1.52$ & 0.249 & 0.94 & $0.71-1.23$ & 0.627 & 0.99 & $0.73-1.32$ & 0.924 \\
\hline Interpersonal conflict & 1.75 & $1.52-2.02$ & $<0.001$ & 1.78 & $1.55-2.06$ & $<0.001$ & 1.22 & $1.05-1.44$ & 0.012 \\
\hline Job insecurity & 1.58 & $1.36-1.85$ & $<0.001$ & 1.59 & $1.36-1.87$ & $<0.001$ & 1.16 & $0.97-1.39$ & 0.095 \\
\hline Organizational system & 1.16 & $0.91-1.49$ & 0.227 & 1.13 & $0.88-1.45$ & 0.359 & 0.97 & $0.74-1.28$ & 0.844 \\
\hline Lack of reward & 1.40 & $1.23-1.60$ & $<0.001$ & 1.39 & $1.22-1.58$ & $<0.001$ & 1.11 & $0.96-1.27$ & 0.154 \\
\hline Occupational climate & 1.37 & $1.06-1.79$ & 0.017 & 1.53 & $1.17-1.99$ & 0.002 & 1.10 & $0.82-1.48$ & 0.533 \\
\hline
\end{tabular}

*demographics (age, marital, education, AUDIT, smoking) were entered as covariates in model 1 and CESD was adjusted in model 2 , ${ }^{\dagger}$ seven subscale scores of KOSS-SF were calculated using a 100-point system. Based on the median of the converted scores, a low-stress group (bottom 50\%) was reference group. KOSS-SF: Korean Occupational Stress Scale-Short Form, AUDIT: Alcohol Use Disorder Identification Test, CESD: Center for Epidemiological Studies Depression

Tables 3 and 4. For males, after adjusting for demographic variables (age, marital status, educational attainment, alcohol use, and smoking), all variables for occupational stress were associated with increased risk of suicidal ideation (job demand $\mathrm{OR}=1.41,95 \% \mathrm{CI}=1.30-1.54$; insufficient job control $\mathrm{OR}=1.29,95 \% \mathrm{CI}=1.06-1.57$; interpersonal conflict $\mathrm{OR}=1.50$, $95 \% \mathrm{CI}=1.36-1.67$; job insecurity $\mathrm{OR}=2.05,95 \% \mathrm{CI}=1.74-$ 2.42; organizational system $\mathrm{OR}=1.21,95 \% \mathrm{CI}=1.01-1.46$; lack of reward $\mathrm{OR}=1.75,95 \% \mathrm{CI}=1.60-1.91$; occupational climate $\mathrm{OR}=1.62,95 \% \mathrm{CI}=1.31-2.02)$. Significant variables after adjusting for depression were insufficient job control and lack of reward (insufficient job control $\mathrm{OR}=1.27,95 \% \mathrm{CI}=1.03-1.57$; lack of reward $\mathrm{OR}=1.28,95 \% \mathrm{CI}=1.16-1.40)$. In women, except insufficient job control and organizational system, all of the occupational stresses were related with an increased risk of suicidal ideation after controlling for demographic variables (job demand $\mathrm{OR}=1.28,95 \% \mathrm{CI}=1.13-1.46$; interpersonal conflict $\mathrm{OR}=1.78,95 \% \mathrm{CI}=1.55-2.06$; job insecurity $\mathrm{OR}=1.59$, $95 \% \mathrm{CI}=$ 1.36-1.87; lack of reward $\mathrm{OR}=1.39,95 \% \mathrm{CI}=1.22-1.58$; occupational climate $\mathrm{OR}=1.53,95 \% \mathrm{CI}=1.17-1.99$ ). The only vari- able showing significance after adjusting for depression was interpersonal conflict (interpersonal conflict OR=1.22, 95\% $\mathrm{CI}=1.05-1.44)$.

\section{DISCUSSION}

In this study, we examined the prevalence of suicidal ideation and its relationships to the occupational stress that is thought to characterize the psychosocial work environment in Korea. The prevalence of suicidal ideation among Korean employees was $7.0 \%$ in this study. Previous studies have reported the prevalence of suicidal ideation to range from $2.1 \%$ to $18.5 \%$ in general population. Based on data collected in 17 countries, the cross-national lifetime prevalence of suicidal ideation was $9.2 \%$ in general population. ${ }^{23}$ The rate of suicidal ideation in Korean employees was lower than rates found in earlier reports. Considering that the unemployment is the strongly associated with suicidal ideation, the fact that all of the participants in our study were employed might have an important impact on this result. ${ }^{24}$ 
In 2014, the suicide rate in Korea was 27.3 per 100,000 people, 38.4 for men and 16.1 for women, with men showing a 2.39-fold higher suicide rate. ${ }^{16}$ However, our results show a suicidal ideation rate that is 2.76 times higher in women. This finding is consistent with previous studies that reported that suicidal ideation and attempts were higher in women, although the actual suicide rate was higher in men $(\mathrm{OR}=1.4) .{ }^{25}$ The differences between women and men in suicidal ideation, planning, and attempts reflect sex-based differences in expectations regarding social roles and relationships in Korea.

Our results indicate that workers with suicidal ideation had fewer years of education, drank larger quantities of alcohol, smoked more, and were more likely to be unmarried. Crossnational data regarding suicide demonstrates the consistency of prevalence estimates and risk factors of these outcomes. The mean scores for depression were higher in the suicidal ideation group than the control group, consistent with the findings of several previous studies. ${ }^{4,26-28}$ In marital status, the rate of others (married, divorced, widowed, separated) in males was higher than that of females. Considering that women still suffer higher level of gender discrimination than men in East Asia, they may regard divorced, widowed and separated states as another stigma, and be reluctant to report them frankly.

After adjusting for demographic variables, almost all subscales measuring occupational stress revealed contributions to the risk of developing suicidal ideation in both genders. However, insufficient job control and organizational system were not associated with suicidal ideation in female employees. Considering gender roles and traits, men are expected to be more distressed due to "male" factors, such as role overload in promoting and maintaining their images as successful achievers and providers and excessive pressure and conflict from attempts to exercise leadership. ${ }^{29}$ However, working women typically have greater responsibilities regarding the home and family; thus, the dual role of homemaker and professional might lead to more severe strain than would factors such as low job control and organizational justice. ${ }^{30}$

After adjusting for demographic variables and depression, there were differences in outcomes between males and females. In males, insufficient job control and lack of reward were related to suicidal ideation, with the relationship partially mediated by depression. All subscales except insufficient job control and lack of reward were associated with suicidal ideation and were fully mediated by depression. In females, interpersonal conflicts were related to suicidal ideation and were partially mediated by depression, while job demand, job insecurity, lack of reward, and occupational climate were associated with suicidal ideation and were fully mediated by depression. These results strongly indicate that suicidal ideation is an understandable reaction to occupational stress, and depression is the single most significant mediator of the association between occupational stress and suicidal ideation.

Two models have long been proposed to explain health implications of work stress, the Demand-Control-Support (DCS) model and the Effort-Reward Imbalance (ERI) model. The DCS model postulates that "high-strain" -a combination of high demand, low control and low social support- at work will cause employees to develop psychological stress, which can in turn lead to chronic disease, including depression. ${ }^{6,31-37}$ The ERI model proposes that a negative trade off between costs and gains at work can lead to adverse health effects. Most studies using the ERI model suggest a positive relationship between effort reward imbalance and depression. ${ }^{6,9,38}$ Other than the components of the DCS and ERI model, previous studies have revealed that job insecurity, organizational injustice, and occupational climate are associated with depression. ${ }^{39-46}$

Previous studies have emphasized the importance of clinical depression as the most significant single contributing factor to suicidal ideation. ${ }^{23}$ In this regard, most types of work stress can lead to suicidal ideation through depression. However, depression alone does not always lead to suicide, as the desire to die may be overcome by sufficiently powerful selfpreservation instincts. The two-stage model of outward- and inward-directed aggression is based on an assumption that suicide and violence are expressions of the same underlying aggressive impulse. ${ }^{47-49}$ Aggressive impulses could be a partial mediator between work stress and suicidal ideation. In our study, adjustment for depression attenuated the association between work stress and suicidal ideation. Insufficient job control and organizational system were significant in males, while interpersonal conflict was significant in females. These results suggest that there are gender differences with regard to aggressive impulses as a risk factor of suicidal ideation.

Most previous studies have found that men report fewer symptoms of depression. ${ }^{50}$ Instead of typical depressive symptoms, Walinder and Rutz proposed the concept of "male depressive syndrome," characterized by acting out behavior, low impulse control, antisocial behavior, substance abuse, low stress tolerance, irritability, and restlessness. ${ }^{51}$ Therefore, aggressive impulses represent expressions of depression in males. Angst et al. found qualitative gender differences in the causal attribution of depression, with men tending to attribute depression more to physical and work- and employment-related problems and females to interpersonal problems. ${ }^{52}$ Moreover Confucianism which has had tremendous impact on gender role in Korea, emphasizes that men should serve as the primary wage-earners within traditional family structures and hold control over their work. From this perspective, we can assume that the Korean male workers are more likely to be depressed when they feel as if there is poor reward in their work 
and when they feel as if they have insufficient control over their work. As a result, when men face lack of reward and insufficient job control, they might feel aggression toward their company; consequently, their depression related to suicidal ideation is might be expressed as aggressive impulses.

Women tend to attribute depression more to relationship problems and account for the interpersonal nature of problems in their attempts to identify and solve them. ${ }^{52,53}$ Thus, social support can lead to additional benefits including adaptive inferential feedback from others, resources for problem solving, and exposure to positive events in females. ${ }^{54}$ However, interpersonal conflict could make women feel helplessness if they lack coping mechanisms. Individuals with a low capacity for flexible divergent thinking are unable to identify alternative solutions to their problems and tend to be impulsive. ${ }^{47}$ Reactive aggression is associated with interpersonal rejection and with patterns of emotional dysregulation in the context of interpersonal difficulties. ${ }^{55}$ Weyauch et al. ${ }^{56}$ have reported that, after adjusting for potentially confounding variables, the number of disrupted interpersonal relationships in the preceding year was an important predictor of the impulsiveness of the suicide attempt.

In conclusion, occupational stress plays a significant role in increasing risk of suicidal ideation through worsening of depressive symptoms. Thus companies should concentrate on reducing the rate of depressed workers by screening clinical depression and transferring patients to psychiatrists allied with company for active treatment. Moreover, our study showed gender differences in components of occupational stress associated with suicidal ideation. Therefore, companies should reflect gender differences to formulate optimized policy by giving reasonable reward and sufficient job control to male workers and providing social support to female workers.

Our study had several limitations. First of all, our study population consisted of employees who attended annual health screening at Kangbuk Samsung Hospital health screening centers in Seoul and Suwon, which may limit the generalizability of our findings to other populations. In this study, only suicidal ideation was investigated, and therefore we cannot comment on whether occupational stressors are associated with committed suicides. Future studies using psychological autopsy designs are required to assess occupational stress among those who have succeeded in suicide. We did not assess possible variables known to be associated with suicidal ideation such as religion, income status and personality. Moreover, specific types of occupation, company size, years of work and weekly working hours were not assessed. Additional research that includes these variables is needed to confirm these findings to better understand the underlying mechanisms between occupational stress and suicide. The cross-sectional nature of this study limited our capacity to draw conclusions about the causal direction of occupational stress and suicidal ideation. For example, suicidal ideation could heighten the experiences and perception of occupational stress, which would contradict our interpretation. In this way, reverse causal or reciprocal relationships might produce misleading findings. The exposure and outcome measures (scores for suicidal ideation, CES-D and KOSS) used in this study were based on self-report questionnaires rather than formal clinical diagnoses. They are thus unlikely to match the accuracy of clinician-based scales, and our results could be affected by response bias. Selection bias might have occurred because we recruited participants from health inspection centers associated with a single hospital, possibly leading to skewed distributions of age, sex, marital status, educational level, and income relative to those of the general Korean population.

Our study also had a number of strengths. We used a large sample, assessing clinical characteristics in large groups of participants with suicidal ideation and controls, allowing for meaningful analysis. Our data were stratified by gender to analyze gender differences in stress dynamics in the workplace. We excluded individuals with physical illnesses at baseline that might have influenced both exposure (occupational stress) and outcomes (the risk of suicidal ideation) and included participants who were of working age (15-64 years) to confirm that we were surveying healthy employees.

\section{Supplementary Materials}

The online-only Data Supplement is available with this article at https://doi.org/10.30773/pi.2017.05.31.1.

\section{REFERENCES}

1. KOSIS. Change in Populations, Statistics 2014. Available at: http://kosis.kr/statHtml/statHtml.do?orgId=101\&tblId=DT_1B34E07\&vw_ cd=MT_ZTITLE\&list_id=D11\&seqNo=\&lang_mode $=$ ko\&language $=$ kor\&obj_var_id=\&itm_id=\&conn_path=E1. Accessed December 19, 2016.

2. de Jonge J, Bosma H, Peter R, Siegrist J. Job strain, effort-reward imbalance and employee well-being: a large-scale cross-sectional study. Soc Sci Med 2000;50:1317-1327.

3. Johnson J, Weissman MM, Klerman GL. Service utilization and social morbidity associated with depressive symptoms in the community. JAMA 1992;267:1478-1483.

4. Kudielka BM, Hanebuth D, von Kanel R, Gander ML, Grande G, Fischer JE. Health-related quality of life measured by the SF12 in working populations: associations with psychosocial work characteristics. J Occup Health Psychol 2005;10:429-440.

5. Stansfeld S, Feeney A, Head J, Canner R, North F, Marmot M. Sickness absence for psychiatric illness: the Whitehall II Study. Soc Sci Med 1995; 40:189-197.

6. Tsutsumi A, Kayaba K, Theorell T, Siegrist J. Association between job stress and depression among Japanese employees threatened by job loss in a comparison between two complementary job-stress models. Scand J Work Environ Health 2001;27:146-153.

7. Jimmieson NL, Terry DJ. Responses to an in-basket activity: the role of 
work stress, behavioral control, and informational control. J Occup Health Psychol 1997;2:72-83.

8. Kawakami N, Haratani T, Araki S. Effects of perceived job stress on depressive symptoms in blue-collar workers of an electrical factory in Japan. Scand J Work Environ Health 1992;18:195-200.

9. Larisch M, Joksimovic L, von dem Knesebeck O, Starke D, Siegrist J. [Effort-reward imbalance at work and depressive symptoms--a cross-sectional investigation of middle-aged employees]. Psychother Psychosom Med Psychol 2003;53:223-228.

10. van Vegchel N, de Jonge J, Bosma H, Schaufeli W. Reviewing the effortreward imbalance model: drawing up the balance of 45 empirical studies. Soc Sci Med 2005;60:1117-1131.

11. Ostry A, Maggi S, Tansey J, Dunn J, Hershler R, Chen L, et al. The impact of psychosocial work conditions on attempted and completed suicide among western Canadian sawmill workers. Scand J Public Health 2007;35:265-271.

12. Tsutsumi A, Kayaba K, Ojima T, Ishikawa S, Kawakami N; Jichi Medical School Cohort Study Group. Low control at work and the risk of suicide in Japanese men: a prospective cohort study. Psychother Psychosom 2007;76:177-185.

13. Amagasa T, Nakayama T, Takahashi Y. Karojisatsu in Japan: characteristics of 22 cases of work-related suicide. J Occup Health 2005;47:157164 .

14. Almasi K, Belso N, Kapur N, Webb R, Cooper J, Hadley S, et al. Risk factors for suicide in Hungary: a case-control study. BMC Psychiatry 2009;9:45.

15. Beehr T, Schuler R. Stress in Organizations. In: Rowland K, Ferris G, Editors. Personnel Management. Boston: Allyn and Bacon, 1980, p.390-419.

16. KOSIS. Suicide rates. Available at: http://www.index.go.kr/potal/main/ EachDtlPageDetail.do?idx_cd=2992. Accessed December 19, 2016.

17. OECD. Suicide rates. Available at: https://data.oecd.org/healthstat/suicide-rates.htm. Accessed December 19, 2016.

18. Radloff LS. The CES-D scale a self-report depression scale for research in the general population. Appl Psychol Meas 1977;1:385-401.

19. Cho MJ, Kim KH. Diagnostic validity of the CES-D (Korean version) in the assessment of DSM-III-R major depression. J Korean Neuropsychiatr Assoc 1993;32:381-399.

20. Chang SJ, Koh SB, Kang D, Kim SA, Kang MG, Lee CG, et al. Developing an occupational stress scale for Korean employees. Korean J Occup Environ Med 2005;17:297-317.

21. Cho HS, Kim YW, Park HW, Lee KH, Jeong BG, Kang YS, et al. The relationship between depressive symptoms among female workers and job stress and sleep quality. Ann Occup Environ Med 2013;25:1

22. Lee BO, Lee CH, Lee PG, Choi MJ, Namkoong K. Development of Korean version of alcohol use disorders identification test (AUDIT-K): Its reliability and validity. J Korean Acad Addict Psychiatry 2000;4:8392.

23. Nock MK, Borges G, Bromet EJ, Alonso J, Angermeyer M, Beautrais A, et al. Cross-national prevalence and risk factors for suicidal ideation, plans and attempts. Br J Psychiatry 2008;192:98-105.

24. Schneider B, Grebner K, Schnabel A, Hampel H, Georgi K, Seidler A. Impact of employment status and work-related factors on risk of completed suicide. A case-control psychological autopsy study. Psychiatry Res 2011;190:265-270.

25. Iribarren C, Sidney S, Jacobs DR Jr, Weisner C. Hospitalization for suicide attempt and completed suicide: epidemiological features in a managed care population. Soc Psychiatry Psychiatr Epidemiol 2000;35:288296.

26. Goodwin RD, Roy-Byrne P. Panic and suicidal ideation and suicide attempts: results from the National Comorbidity Survey. Depress Anxiety 2006;23:124-132.

27. Pilowsky DJ, Olfson M, Gameroff MJ, Wickramaratne P, Blanco C, Feder A, et al. Panic disorder and suicidal ideation in primary care. Depress Anxiety 2006;23:11-16.

28. Sareen J, Cox BJ, Afifi TO, de Graaf R, Asmundson GJ, ten Have M, et al. Anxiety disorders and risk for suicidal ideation and suicide attempts: a population-based longitudinal study of adults. Arch Gen Psychiatry 2005;62:1249-1257.

29. Ivancevich JM, Matteson MT. Stress and Work: a managerial perspective. Glenview, IL: Scott Foresman; 1980

30. Gyllensten K, Palmer S. The role of gender in workplace stress: a critical literature review. Health Edu J 2005;64:271-288.

31. Karasek RA. Job demands, job decision latitude, and mental strain: implications for job redesign. Adm Science Quarterly 1979;24:285-308.

32. Siegrist J. Adverse health effects of high-effort/low-reward conditions. J Occup Health Psychol 1996;1:27-41.

33. Karasek RA, Theorell T. Healthy Work: Stress, Productivity, and the Reconstruction of Working Life. New York: Basic books; 1992.

34. Paterniti S, Niedhammer I, Lang T, Consoli SM. Psychosocial factors at work, personality traits and depressive symptoms. Longitudinal results from the GAZEL Study. Br J Psychiatry 2002;181:111-117.

35. Mausner-Dorsch H, Eaton WW. Psychosocial work environment and depression: epidemiologic assessment of the demand-control model. Am J Public Health 2000;90:1765-1770.

36. Aziah BD, Rusli BN, Winn T, Naing L, Tengku MA. Prevalence and associated factors of job-related depression in laboratory technicians in Hospital Universiti Sains Malaysia (HUSM) and Ministry of Health Malaysia (MOH) Hospitals in Kelantan. Med J Malaysia 2004;59:268-278.

37. Ahola K, Honkonen T, Kivimaki M, Virtanen M, Isometsa E, Aromaa A, et al. Contribution of burnout to the association between job strain and depression: the health 2000 study. J Occup Environ Med 2006;48: 1023-1030.

38. Siegrist J, Starke D, Chandola T, Godin I, Marmot M, Niedhammer I, et al. The measurement of effort-reward imbalance at work: european comparisons. Soc Sci Med 2004;58:1483-1499.

39. Elovainio M, Kivimaki M, Vahtera J. Organizational justice: evidence of a new psychosocial predictor of health. Am J Public Health 2002; 92:105-108.

40. Kivimaki M, Elovainio M, Vahtera J, Virtanen M, Stansfeld SA. Association between organizational inequity and incidence of psychiatric disorders in female employees. Psychol Med 2003;33:319-326.

41. Kivimaki M, Vahtera J, Elovainio M, Virtanen M, Siegrist J. Effort-reward imbalance, procedural injustice and relational injustice as psychosocial predictors of health: complementary or redundant models? Occup Environ Med 2007;64:659-665.

42. Price RH, Choi JN, Vinokur AD. Links in the chain of adversity following job loss: how financial strain and loss of personal control lead to depression, impaired functioning, and poor health. J Occup Health Psychol 2002;7:302-312.

43. Claussen B, Bjorndal A, Hjort PF. Health and re-employment in a two year follow up of long term unemployed. J Epidemiol Community Health 1993;47:14-18.

44. Johansson SE, Sundquist J. Unemployment is an important risk factor for suicide in contemporary Sweden: an 11-year follow-up study of a cross-sectional sample of 37,789 people. Public Health 1997;111:41-45.

45. Lewis G, Sloggett A. Suicide, deprivation, and unemployment: record linkage study. BMJ 1998;317:1283-1286.

46. Chun H, Doyal L, Payne S, Il-Cho S, Kim IH. Understanding women, health, and social change: the case of South Korea. Int J Health Serv 2006;36:575-592.

47. Barzilay S, Apter A. Psychological models of suicide. Arch Suicide Res 2014;18:295-312.

48. Bridge JA, Goldstein TR, Brent DA. Adolescent suicide and suicidal behavior. J Child Psychol Psychiatry 2006;47:372-394.

49. Corruble E, Damy C, Guelfi JD. Impulsivity: a relevant dimension in depression regarding suicide attempts? J Affect Disord 1999;53:211-215.

50. Wilhelm K, Parker G, Asghari A. Sex differences in the experience of depressed mood state over fifteen years. Soc Psychiatry Psychiatr Epidemiol 1998;33:16-20.

51. Walinder J, Rutzt W. Male depression and suicide. Int Clin Psychophar- 
macol 2001;16(Suppl 2):S21-S24.

52. Angst J, Gamma A, Gastpar M, Lépine JP, Mendlewicz J, Tylee A, et al. Gender differences in depression. Eur Arch Psychiatry Clin Neurosci 2002;252:201-209.

53. Davila J, Hammen C, Burge D, Paley B, Daley SE. Poor interpersonal problem solving as a mechanism of stress generation in depression among adolescent women. J Abnorm Psychol 1995;104:592-600.

54. Kleiman EM, Riskind JH. Utilized social support and self-esteem me- diate the relationship between perceived social support and suicide ideation. A test of a multiple mediator model. Crisis 2013;34:42-49.

55. Conner KR, Duberstein PR, Conwell Y, Caine ED. Reactive aggression and suicide: theory and evidence. Aggress Violent Behav 2003;8:413432.

56. Weyrauch KF, Roy-Byrne P, Katon W, Wilson L. Stressful life events and impulsiveness in failed suicide. Suicide Life Threat Behav 2001;31:311319. 